\title{
JULIAN AYUQUE: NARRATIVIDAD Y CONFLICTO CULTURAL
}

\author{
Rommel Plasencia Soto ${ }^{1}$
}

Universidad Nacional Mayor de San Marcos, Lima

http://dx.doi.org/10.5209/rev_NOMA.2013.42358

Resumen.- Artículo que nos revela a un escritor cuya temática es el paisaje y la historia de los pueblos de Huancavelica. A través de él, se intenta rastrear su genealogía literaria y establecer una comparación con la llamada literatura andina, tributaria de la memoria y de la tradición oral.

Palabras clave.- indigenismo, huancavelica, literatura andina, provincias quechuas

Abstract.- Article that reveals a writer expropriated and whose theme is the landscape and the history of the Huancavelica peoples. Trough the, you are tryng to trace of genealogy literary and establish a comparison the Andean call literature, tax of the memory and the oral tradition.

Keywords.- indigenismo, Huancavelica, andean literature, quechua provinces

El lector tiene conciencia de revelar y crear a la vez, de revelar creando, de crear por revelación [Jean Paul Sastre]

La narrativa andina peruana entendida como el tema andino (el paisaje, la trama o la historia) ha tenido básicamente dos momentos crepusculares. El primero estuvo relacionado con el movimiento indigenista de la primera mitad del siglo XX. El segundo estuvo asociado a la renovación en el lenguaje y el tratamiento que le dio José María Arguedas y que se va desprendiendo lentamente de las influencias del primer momento.

Este segundo momento que bien se puede denominar como de la narrativa andina contemporánea, tuvo con el tratamiento literario que se le dio al conflicto interno de los 80, un impulso que le permitió nuevas técnicas, facturas y sobre todo pensar lo andino ya no como una respuesta a la intelectualidad criolla o limeña, sino la de comprometer en su reflexión, el futuro del Perú mismo como país y como una nación en permanente conflicto social y cultural. ${ }^{2}$

Sin embargo entre esos dos ejes se procreó una literatura denominada de "provincias" no sólo porque sus autores fueron tales: escritores sólo conocidos en ámbitos regionales o departamentales, que publicaron en pequeñas

\footnotetext{
${ }^{1}$ Universidad Nacional Mayor de San Marcos, Lima.

2 Un texto pionero en ese sentido sería "Con los ojos siempre abiertos" (1990) de Luís Nieto Degregori.
} 
editoriales efímeras o revistas universitarias. Es decir periféricos y con un campo (de enunciación) poco hegemónico respecto del canon central. ${ }^{3}$

Formato y canon, que en un país con elaboradas jerarquías sociales y étnicas, también se reproduce con la diferenciación de los prestigios culturales. Decimos también de "provincias" porque los temas de esta narrativa fueron minimalistas y cuyos cercos no sobrepasaban los de una provincia o una escena cotidiana y sin embargo como veremos más adelante, fueron temas que destilaban problemas reales y con gran significado para amplios sectores de la población rural.

Estos intelectuales diferían no sólo por la tecnología literaria y los círculos de influencia por los que transitaban, sino también por sus propósitos políticos. Por ejemplo la diferencia entre "La hora azul" (2005) de Alonso Cueto y "La violencia del tiempo" (1991) de Miguel Gutiérrez, expresarían esa coexistencia y esa pugna en al campo cultural como un apéndice del conflicto entre diversas clases sociales, entre distintas experiencias de consumo cultural y de recursos para abjurar lo indeseable.

\section{Intelectuales y nación}

Estudiar esta nueva narrativa es entender en primer lugar, los procesos de modernización y la (consiguiente) creación de una comunidad de intelectuales que van teniendo conciencia de su posición al ejercer la representación literaria de sus regiones.

Este aspecto es parecido a otros cielos en donde se ha relacionado la modernización del Estado con la aparición de conciencias nacionales (y étnicas) que cobijados en sus experiencias cosmopolitas y sus orígenes extrarurales, reformularon sus tradiciones con propuestas de autonomía extraídos de las diversas fases de su aprendizaje intelectual.

Por ejemplo Amílcar Cabral (1973) y sobre todo Mudimbe (1988) anotaron como los intelectuales africanos después de la segunda postguerra, rechazaron muchas veces los conceptos europeos confeccionados para su continente. Fueron suspicaces en desarmar la formidable construcción cartográfica y textual realizada por el colonialismo. Como por ejemplo el hecho de acentuar las "costumbres salvajes" y afianzar la superioridad europea, al narrar lo exótico y remarcar la extrañeza de sus formas de organización social.

Pero cuando los intelectuales nacionalistas bebieron de la literatura anticolonial curiosamente la antropología africanista abogó por el "retorno a las fuentes" para de ese modo aliarse políticamente con las elites nativas y evitar los arrestos radicales de un Patricio Lumumba. ${ }^{4}$

\footnotetext{
${ }^{3}$ Mucha tinta ha corrido sobre el tema del indigenismo literario. Por ejemplo Nieto (2000) plantea que en la literatura peruana es innegable la pugna entre "criollos" y "andinos" y que estos últimos esta conformada por las élites provincianas. Ese no es nuestro caso. Quizás no estemos lejos de lo que Paul Auster llamó una "guerra civil cultural".

${ }^{4}$ Cabral apuntaba "No es, pues, casual que teorías o "movimientos" del tipo del panafricanismo y la negritud (dos expresiones pertinentes, que se inspiran fundamentalmente en el postulado de la identidad cultural de todos los africanos negros) hayan sido concebidas fuera del África negra" (1973:15)
} 
Otro caso que nos puede ilustrar es el de la llamada generación del 98 español. La sensación de incompletitud que significaba su atraso respecto del resto de Europa aunada a la pérdida de sus últimas colonias, hizo que el paisaje de Castilla con su historia y su lengua sonora, fuesen la inquietud de los intelectuales que Fox (1997) ha llamado "retrocasticistas".

Es decir aquellos que abogaban por el progreso, la libre enseñanza y la desamortización pero que curiosamente se afirmaban en la historia, el paisaje (la intrahistoria de Unamuno) y los valores al que supuestamente estaban asociados los españoles: el idealismo, el heroísmo, el misticismo y el amor por la raza.

En América, la lógica colonial de subordinación criolla ante los peninsulares fue también paradójicamente el fundamento de su superioridad frente el conjunto mestizo, negro o indígena en las nuevas repúblicas del siglo XIX. Por eso la imposibilidad de una modernidad plena, pues esta se refugiaba sólo en el discurso y el ritual como un acto de representación (y de nominación), pero ausente en el allanamiento de los abismos sociales y étnicos heredados del antiguo régimen.

\section{Modernidad y tradicionalismo en los Andes peruanos}

Por eso, indigenismo del Perú del siglo XX, el movimiento intelectual que narró y representó al conjunto indígena entendido como el cimiento de una nación fue en cierto modo suave.

Si bien muchas de estas tradiciones regionales (sobre todo en el Cuzco y Puno) se habían inscrito merced a este movimiento, en corrientes de innovación literaria y artística, se ha reconocido también, que en ausencia de una modernidad real (entendida como la participación política directa del mundo indígena), se prodigaron a si mismos, sólo una modernidad simbólica y representacional.

Para Cynthia Vich (2000), el discurso indigenista sería sólo un "espasmo socio-cultural", en el cual el proyecto cultural fue inconcluso al no tener una relación con un proceso social y político definido (la erradicación de las bases coloniales) y asentarse definitivamente como una etapa histórica de modernidad. Mirko Lauer (1997) concluye en que lo autóctono en el arte indigenista no solo fue visto como lo "remoto" y lo "diferenciado" sino que también fue contemplable sólo desde la distancia y que se tradujo en lo pintoresco: el paisaje es representado como tosco (telúrico) y monumental (pétreo y por lo tanto indestructible y atemporal).

Algo parecido ha sido mencionado cuando se ha descrito la literatura de viajes hecha por los exploradores blancos sobre África y América. Sólo se narra y se pinta cuando el ejecutor se desliga de la actividad productiva y que representa el tiempo del ocio y de ejercicio intelectual propios del capitalismo. Es decir los campesinos no se detienen ante los celajes ni se arroban ante los sentimientos estéticos que producen las montañas; ${ }^{5}$ eso sólo lo hacen los mistis o los intelectuales provincianos en la escena urbana (como podrían serlo Porfirio Meneses, Rubén Sueldo Guevara o José Sabogal).

\footnotetext{
${ }^{5}$ Es lo que Pratt (2010: 153) ha llamado el "narcisismo de los sentimientos".
} 
En ese sentido, el departamento de Huancavelica a diferencia de sus vecinos como el valle del Mantaro o Ayacucho, no tuvo un movimiento regional de escritores que representasen tempranamente a su región.

En el valle del Mantaro del departamento de Junín, los escritores se nuclearon en Jauja alrededor de Abelardo Solís intelectual socialista y amigo de Mariátegui y que tenía en común con el autor de los "Siete ensayos...", su reflexión sobre el campesinado indígena y el problema de la tierra. Estos escritores (entre los que se cuentan Espinoza Bravo, Bonilla del Valle y Modesto Villavicencio) no sólo celebraron el paisaje luminoso de la sierra central sino también, el rechazo militante a la empresa norteamericana Cerro de Pasco Corporation instalada en la región.

Fue ciertamente un movimiento si bien heterogéneo, activo intelectualmente pero sin el prestigio que tomaría el indigenismo sureño. Sin embargo Manuel Baquerizo (1998:37) anota que "Este olvido no deja de ser lamentable, si reparamos en que los escritores de nuestra región fueron quienes impulsaron con mayor audacia que en la Capital las corrientes vanguardistas y proletarias en la literatura" y luego remarca "Un dato revelador de la enorme efervescencia intelectual que imperaba entonces, es que Junín ocupaba en la década del veinte, el segundo lugar, en número de revistas y periódicos publicados en el país" (40).

Quizás este auge regional tuvo como antecedentes que entre los años de 1916 y 1919 tuvo como impulsores a Pedro Zulen e Hildebrando Castro Pozo, quienes residieron en la región e incluso este último, escribiría "Nuestra comunidad indígena" en la ciudad rural de Jauja en donde a su vez intercambiaba cartas con el Amauta (Arroyo1980).

En Ayacucho (particularmente en sus provincias norteñas) fue más bien una mirada señorial (Parra Carreño, Moisés Cavero o Pío Max Medina) de la región para re-inventarse y homologarse así con el indigenismo cuzqueño y enfrentar los radicales cambios que produjo el presidente Leguia al acercar el departamento hacia la costa mediante el sistema de conscripción vial; debilitando de ese modo el estatus de sus clases dominantes.

Esta re-invención del regionalismo cultural para exaltarse y narrarse como un pueblo con profundas raíces históricas como fue el caso de los pocras, ha sido cuestionada por Jaime Urrutia (1994) al proclamar esa supuesta filiación prehispánica, como un mito huamanguino.

Huancavelica en cambio, tuvo un retraso en el surgimiento de escritores propios que fueran portavoces de su tierra y de sus hombres. No sería sino hasta los años 50 en que la modernización de Estado, la ampliación de la educación pública y la migración creciente de sus clases medias hacia la costa, es que aparecería el primer grupo de narradores. Esto por supuesto estaría también ligado a la crisis de la clase terrateniente tradicional y la bancarrota de su reproducción ideológica.

Por ejemplo, Tulio Carrasco (1933-2010) se alinea con el modernismo en su narrativa corta pero tomando como insumo su experiencia como hijo de hacendado y por lo tanto, sagaz en la mirada ruralista de su región.

Miembro de la generación del 50, estudió letras y derecho en la Universidad Católica y fue asiduo concurrente del Palermo en donde se reunía entre otros 
con Julio Ramón Ribeyro. Publicó en 1955 "Mala entraña: cuentos del ande" que es de limpia factura neo-realista. "Tulio Carrasco nos trae en su estado simple, el tono rural del hombre apegado al agro y el mensaje de su tierra estratosférica e ignorada: Huancavelica", dice inequívocamente la contratapa del libro.

Conformado por diez cuentos, de los cuales dos ("Mala entraña" y "El macho del pueblo") están ambientados en Junín y un pueblo fronterizo con la selva peruana. El resto son relatos huancavelicanos francamente intemporales y que suceden en ningún lugar (nowhere). Sin embargo la estructura está bien planteada y registran un buen conocimiento de la realidad rural.

"Antucha Huaylli" figura en los "Cuentos peruanos contemporáneos" reunida por Alberto Escobar $(1958)^{6}$ y "El látigo" se incluye en la colección de cuentos sanmarquinos realizado por Carlos Eduardo Zavaleta y Sandro Chiri en el 2002. En ambos, la peculiaridad del ambiente serrano aprisiona al argumento.

El caso de Sergio Quijada Jara (1914-1990) es también significativo en la narrativa huancavelicana. Su obra esta vinculada al registro folklórico y en cierto modo esclarece el paisaje social del departamento (y en particular de Tayacaja). Sus frescos narrativos se comprometen con la cultura, animando la nostalgia por lo rural, lo típico y lo pre-moderno.

Natural del anexo de Magdalena en Acostambo que casi es una frontera con la región wanka de Junín, se graduó de abogado en San Marcos en 1945. En 1940 obtiene una mención honrosa en los Juegos Florales Universitarios con "Estampas huancavelicanas" que sería publicado en 1944.

En "Canciones del ganado y pastores" (1957) que se presenta con una introducción del etnólogo Paúl Rivet, recopila 200 canciones, la mayoría vinculadas a la fiesta ganadera del Santiago y entonadas en el valle del Mantaro y los pueblos de Huachocolpa, Surcubamba, Salcahuasi y Colcabamba en la provincia de Tayacaja:

\author{
Las astas de mi vaca \\ Son cuernos, dices, \\ Es linda espada de oro. \\ II \\ La pelambre de mi vaca \\ Es simple pelo, dices, \\ Su pelito es linda felpa. \\ III \\ La pezuña de mi vaca \\ Es uña, dices, \\ Su pezuña de zapatito bayo.
}

Además su labor de investigación folklórica le ganaría la amistad y la admiración de intelectuales como Efraín Morote y Arguedas. Este registro de los ritos, canciones y costumbres rurales ha inspirado también, estudios de etnografía contemporánea como los realizadas por el antropólogo Alejandro

\footnotetext{
${ }^{6}$ En esa antología también figuran Ribeyro, Vargas Vicuña y Congrains.
} 
Ortiz cuando ha hurgado el tema de los amores pastoriles (Ortiz 1993) e incluso se replica su formato en "La sangre de los cerros" (1987), el cancionero quechua de los hermanos Montoya.

Sin embargo el escritor empezó sus narraciones con invocaciones nostálgicas sobre el terruño. Por ejemplo en "Casita de campo" escribe: "evoco el campo, ese pedacito de tierra solitaria y triste donde se guarneció mi inocencia" al igual que la memoria de los primeros años en "El patio de la otra casa" (1992) del pampino Muñoz Monge o "Warma kuyay" de Arguedas, nos revelan una constante ideológica entre los recuerdos infantiles (madre-casa-terruño) y la acción narrativa de corte indigenista. No es difícil concluir entonces que la nostalgia primordial se convierte luego en el amor por la Nación (patria-madre).

\section{Julián Ayuque y la cuestión de la identidad}

No sólo pretendemos sacar de la sombra a escritores de provincia, sino también ahondar en la comprensión del país desde sus provincias. Como Mariátegui y Salazar Bondy (1974) también votamos en contra de las políticas culturales centralistas y abogamos por una democratización de la producción cultural. No olvidemos que la sociología de la cultura es en sí, un apéndice de la sociología del poder (Bourdieu 1990). La identidad en nuestro país exige también reconocernos como plurales en la producción de discursos y revalorar los nudos narrativos en donde la desigualdad y los conflictos interétnicos sean significativos.

Al igual que Orestes en "Las Moscas" de Sartre, el conocimiento no puede servir para elevarnos por encima de los mortales y contentarnos con su poder distintivo, el conocimiento es tal por su compromiso, un compromiso reparador de lo injusto y lo banal. En ese sentido, es que Julián Bacilio Ayuque Cusipuma ilustra nuestro propósito.

Nacido en el barrio de Arriba del pueblo de Castrovirreyna (Huancavelica) en 1942, fue hijo de Lucas Ayuque Canales comerciante y arriero de la comunidad de Qochas y de Grimalda Cusipuma Peve. Su infancia campesina transcurrió entre los parajes de Cruzpata y Cochas. Quechuahablante, ingresa a los diez años a la Escuela Prevocacional Nro.554 de Castrovirreyna, donde recién aprende su segunda lengua, el castellano.

"Cuidaba mis vaquitas, retozando de igual a igual con los becerritos robustos; desmenuzaba con barreta los terrones del barbecho; guiaba los bueyes del con el gañan laborioso; sacaba la papa tirando gozoso con las más grandazas a mis compoblanas que vestían polleritas de diferentes colores...."

Llega por primera vez en 1959 a la ciudad de Huancavelica la capital departamental, ahí reside en el barrio de Yananaco, el barrio de los botones cutichis, de aliento migrante y plebeyo. El mismo lo describe con elocuencia:

"Quedé gratamente impresionado de los arbustos de ayrampo; del río Ichu, vena y corazón de la ciudad; del majestuosísimo cerro Potoqchi, testigo intachable de la historia huancavelicana; de las casas construidas con piedras labradas amarillentas; de la fachada principal de la catedral de pura piedra colorada, esculpida en alto y bajo relieve, desafiando a las tempestades; y del tan tan de la vieja campana del reloj de la catedral, anunciando las horas" 
Cursa la educación secundaria en la Gran Unidad Escolar "La Victoria de Ayacucho" cuanto esta funcionaba en el viejo local de la iglesia San Francisco de Asís. En el prestigioso colegio tendría como profesores a Larrauri de Matemática, Requena "el chuto" que "se desempeñaba con eficiencia en el dictado de Geografía e Historia Universal", Retamozo "Soflitas", quien enseñaba Castellano; Mendoza "Bufanditas", que tenía a su cargo Álgebra y Geometría, Santiago Cabrera Cochama "Cachoma", suboficial del ejército y encargado de la instrucción pre-militar "De campaña nos llevaba a comunidades distantes, durante una semana. En el momento que pasábamos por pantanos ordenaba: "iAvión, avión!" Teníamos que tirarnos al lodo.”

Las clases de literatura española de Juan Chacón Remigio en donde fraguó su vocación por las letras, fueron estimulantes para el joven Ayuque. El doctor Almeida "Buldog" abriendo el texto de Psicología de Telmo Salinas y dictándolo todo y casi al pie de la letra.

En el año 60, aprovechando que su cuñado Rogelio trabajaba en la mina Carmen de Huancavelica, empezó a trabajar como pequeño comerciante trayendo uvas e higos de Pisco y vendiéndolos a los trabajadores.

En 1961 entra a trabajar como despachador en la Mercantil de la mina Caudalosa. En sus vacaciones de 1962 llega a la hacienda Bernales de Pisco, donde se emplea de lampero, donde debido al clima y quizás el exceso de trabajo se enferma y regresa a Castrovirreyna: "Pedí mi cancelación y retorné a mi añorada tierra, llevándome como grato recuerdo la imagen de Canti, de los parrales, platanales, sandiares, las frondosas higueras, los interminables algodonales y de los bosques de carrizos de ambas orillas del río".

Ingresa en 1965 a la Facultad de Educación de la Universidad Nacional del Centro del Perú (UNCP), ahí cursaría la especialidad de Español y Literatura. La antigua Facultad funcionaba en ese entonces en una casona de la segunda cuadra del jirón Cuzco en Huancayo. Recuerda que en sus aulas luego de leer a Mariátegui, el "Tungsteno" de César Vallejo y "algunos periódicos de la Federación Universitaria de San Marcos por propia iniciativa y posición de clase" abraza las ideas socialistas.

Este momento importante en la vida de nuestro escritor merece algunas líneas. La Universidad de Huancayo fue creada en 1958 con el nombre de Universidad Comunal del Centro, su constitución se debía al esfuerzo de las comunidades campesinas del departamento de Junín. Estas comunidades ya habían sido protagonistas de la ausencia de instituciones regidas por la servidumbre (Arguedas 1957), y su despliegue autónomo había permitido la expansión de una próspera economía mercantil, acicateada por el trabajo asalariado en las minas de la región, trayendo consigo una mayor migración, mercantilización y diferenciación social.

Es por ello que las comunidades tendrán un papel protagónico en los movimientos regionales y que después se expresaría en las tomas de tierras de las haciendas ganaderas en las altiplanicies del departamento de Junín (Rénique 1978). Agrupadas en una Federación de Comunidades, eran según Gavin Smith (1989) la expresión política de una "clase media comunal". 
Por presión de sus dirigentes -entre los que destacan el huasicanchino Elías Tácunan y el sicaíno Canchucaja-, la Universidad se nacionaliza en 1959 con los auspicios del partido aprista, en donde Ramiro Prialé y Javier Pulgar Vidal animan sus primeras comisiones.

Lo novedoso de su creación fue que por primera vez una universidad peruana se fundaba con filiales ubicadas fuera del departamento: poseía sedes en Huanuco, Cerro de Pasco, Huacho y Lima; que poco después adquirirían personalidad propia, por ejemplo, la sede en Lima se convertiría en la Universidad Nacional Federico Villarreal. De igual modo, con el auspicio de esas mismas comunidades se crearon de forma inédita carreras que se suponía correspondían con las necesidades de la región y que exigían un impulso desarrollista para explotar los recursos y ampliar su mercado interno regional. En su primer prospecto por ejemplo, figuran carreras como Arquitectura, Zootecnia, Ingeniería Forestal o Antropología y Desarrollo Comunal y que eran la muestra de sus ansias de autonomía productiva bajo el liderazgo comunero. ${ }^{7}$

"Los catedráticos en su mayoría pertenecientes a ese partido, a los estudiantes de izquierda, tomaban represalias con las notas" "Sin embargo hubo catedráticos honestos y justos como Waldemar Espinoza Soriano, erudito y profundo conocedor de la ciencia histórica, semanalmente nos hacía leer un libro" "Maurilio Arriola Grande, Decano de la Facultad de Educación, dictaba Literatura Universal, al pie de la letra, de una copia mimeografiada voluminosa de San Marcos.." y "El Dr. Emilio Vásquez "Censhas" (le pusimos ese apodo porque a ciencias pronunciaba "censhas"), conocía la pedagogía, fue muy justo en poner notas"

Sin embargo poco después el malestar estudiantil no se dejaría esperar. El partido aprista que había tomado las riendas de la universidad había instalado una red de clientelismo que impedía un mejoramiento académico y que además permitía un manejo abusivo de sus bienes y de sus fondos.

En septiembre de 1968 "después de una asamblea de estudiantes en el Aula Magna de ésta, cerramos la puerta, alegando toma de local para luchar contra la inmoralidad del Rector Nilo Arroba Niño y la reorganización de la UNCP".

El grupo de estudiantes que participó de la toma de la universidad (entre ellos Ayuque) fue expulsado por las autoridades apristas. El golpe militar de Velasco en octubre del 68, dejó sin efecto la expulsión y se decretó inmediatamente la reorganización de la Universidad, devolviendo de nuevo a sus aulas a los alumnos insurgentes. Ya casi terminando la carrera, Julián se desempeña como Ayudante de Cátedra de Literatura Moderna y Contemporánea.

\section{Su labor docente}

Opta el grado de Bachiller en Humanidades en noviembre de 1971 y el Título de Profesor de Educación Secundaria en la especialidad de Español y

\footnotetext{
${ }^{7}$ De igual modo la antigua Escuela de Ingenieros fue la respuesta de una burguesía que necesitaba de innovación tecnológica ante un espectro de pequeña minas ubicadas sobre todo en Junín, Pasco y Huarochirí. Con la llegada a principios del siglo XX de la compañía Cerro de Pasco Corporation es que se cancela ese esfuerzo autonómico (López-Soria 1981).
} 
Literatura el siguiente año. De 1973 hasta abril de 1978 fue profesor en la Universidad del Centro. En mayo del 75 entra a trabajar como docente especialista del Ministerio de Educación, con ese cargo transita por Pariahuanca, Chacapampa (distritos de la provincia de Huancayo) y Huaribamba en Tayacaja. En enero de 1980 gana un concurso para hacerse cargo como asesor del área de Lenguaje y Literatura del Colegio Santa Isabel, donde trabajó gran parte de su vida hasta su jubilación en 1996.

Santa Isabel es un viejo colegio fundado por el liberal Sebastián Lorente en 1851, un murciano que llegaría a la sierra central para curarse de la tuberculosis. Colegio emblemático, albergó a todas las clases sociales en una ciudad igualitaria como Huancayo. En él por ejemplo, José María Arguedas haría sus primeros escarceos literarios. Dos publicaciones, Ondas Isabelinas ${ }^{8}$ y el Amauta Isabelino, fueron la tribuna de las poesías y las primeras narraciones de Julián Ayuque.

\section{Imaginario literario y político}

Ayuque a diferencia del folklorismo de Quijada Jara o del realismo señorial de Tulio Carrasco, puede ser catalogado como un escritor indio. Su tesis de bachillerato puede ofrecernos el vector para analizar su mirada y su representación de lo andino. A diferencia de sus cuentos y de su novela El noble manchego (1984), su tesis no se fundamenta en la memoria.

Pues como ya hemos mencionado, la memoria es el principal mecanismo creativo en la narrativa andina. Aunque como menciona Marc Augé "la memoria se aferra al mito más que a la historia" (1998: 72). Lo crucial es entonces, ubicar los principios y las coordenadas elementales de esa memoria andina. ${ }^{9}$

"El Wamani en la Agonía de Rasu-Niti de José María Arguedas", fue presentado como tesis de Bachiller en 1971. Tesis asesorada por Julio Díaz Falconí, catedrático iqueño de origen sanmarquino y quien había publicado un interesante ensayo sobre la imagen de la muerte en Valdelomar.

En sus 58 páginas se adentra en la tarea de descodificar el significado de las montañas sagradas en los andes del sur ayacuchano, que es donde está ambientado el cuento de Arguedas. Las montañas en los Andes (y en otras sociedades) son sagradas, porque rompen la cotidianeidad del paisaje, también porque establecen una conexión entre el cielo y la tierra y porque su figura vertical nos evoca el poder de las formas fálicas.

En el área andina, el tránsito por su zona de influencia (la puna y las qochas) esta extremadamente ritualizado. Emerge en oposición al espacio secularizado de la comunidad: comunidad/montaña, chacra/pastoreo, socializado/salvaje, femenino/masculino, riego/rayo-Iluvia; comprometiendo a una serie de intermediarios para manipular o canalizar su fuerza.

El wamani pues otorga fuerza no sólo a los laikas dándoles una visión, sino también al bailarín de tijeras, el danzaq. Es por eso que realizan proezas

\footnotetext{
${ }^{8}$ Ondas Isabelinas fue fundada en 1916 y tuvo como primer director al pampino César Edmundo Monge Sánchez.

${ }_{9}^{9}$ Dicen que el tiempo y el olvido/Son como hermanos gemelos/Que vas echando de más/Lo que un día echaste de menos/ Estopa.
} 
extraordinarias que han sido asociadas al chamanismo y al baile extático. Por ello recurre a espacios vedados y ocultos: el atrio o los muros posteriores de una iglesia, dietas rigurosas y abstinencia sexual, manipulación de metales y animales considerados "diabólicos" por la evangelización colonial (sapos, pequeñas culebras e insectos).

El folklore le ha dado un colorido despliegue narrativo (Arroyo Aguilar 1987) y la moderna etnografía ha sustentado valiosos estudios en donde insertan su significado en el mundo ceremonial y simbólico andino (Merlino 1983, Flannery 1989 y Ricard 2007).

El estudio de Arguedas sobre Puquio publicado en 1956 nos habla sobre el significado casi religioso de los wamanis entre los ayllus quechuas. De este modo "La agonía de Rasu-Niti" es una narración elegíaca sobre un dansaq, de su muerte y de su resurrección. Además en este trabajo es que la etnografía y la invención literaria se conjugan. ${ }^{10}$

Casi fronterizo - quizás esa sea la palabra que defina con exactitud al novelista andahuaylino, fronterizo no solo en su producción sino también en su lenguaje y en sus sentimientos- entre el realismo mágico y el memorial de la danza. El protagonista Pedro Huancayre entra y sale por distintos mundos, pero enmarcados en la miseria de un pueblo en donde la división entre indios, señores y mestizos es devastadora.

Ayuque asume en su estudio, la postura fenomenológica de Mircea Eliade sobre la religión y cuya definición más visible son las hierofanias: la irrupción de lo sagrado en este mundo. Esta irrupción se expresa en lugares, tiempos y personas, en que lo sagrado no sólo va cubriendo lo profano sino que a la vez, lo separa rigurosamente.

En "La agonía.." se reconoce un tiempo sagrado cuando el Wamani se presenta "cuando el Sol ya había pasado el centro del cielo" y lo compara con su propia experiencia cuando afirma que en Huancavelica "existe la creencia de que el Wamani aparece en chaupi tuta (medianoche), chaupi punchau (mediodía), intipasayta (atardecer) e intilloqsimuyta (puesta del sol)" (1971:4). El Wamani además tiene el poder de la transmutación y en el caso del cuento de Arguedas, es un cóndor quien recibe la fuerza y el alma del cerro tutelar. También el danzante recibe esa fuerza y es poseído para luego transmitírselo a su discípulo Atoq'sayku en un caso típico de iniciación:

"!El Wamani aquí! ¡En mi cabeza! ¡En mi pecho aleteando- dijo el nuevo danzaq"

Rasu Ñiti, es efectivamente un intermediario. Puede ser visto como un personaje ambiguo en la que su salvación/condenación ejerce temor y fascinación a la vez. Es la característica de lo sagrado como "manantial de toda eficacia" según la feliz expresión de Roger Callois (1996:14) y que retoma en esta definición, las ideas rectoras de Durkheim. Toda su "técnica" comunicativa es de ascetismo y de ofrenda hacia lo sobrenatural: "Así los sagrado, que no

\footnotetext{
${ }^{10}$ Recientemente Landa (2010:129-154) ha expresado que Arguedas "nos engañó" pues en su obra etnológica también estaría presente la factura y la trama literaria. Quizás esto sea cierto para su estudio comparativo entre las comunidades de España y del Perú, pero no para sus estudios sobre la sierra central, en ellos se nota una resuelta racionalización sobre el mestizaje y la modernización.
} 
puede rechazar ese obsequio usuario, se convierte en deudor del donante, queda comprometido por lo que recibe y para no quedarse atrás debe conceder lo que se le pide: ventaja material, virtud, o indulto del castigo. Entonces el orden del mundo se restablece" (Callois 22).

En él se conjugan la individualidad rural que se desea trascender a través de la inmortalidad y la naturaleza cósmica del Ande. Los dos elementos finales en la agonía del danzante son la música que concluye con el Yawar Mayu que es el "paso final que en todas las danzas de indios existe" y el río "cargado y turbio", que representa el movimiento y el huayco, símbolo del cataclismo y de la renovación.

Ya en Los ríos profundos, la metáfora del río tendrá su máxima expresión ${ }^{11}$ : el río va hacia la tierra de los Antis, el mundo de los chunchos y el de los muertos donde el orden social se invierte. En síntesis, Ayuque quiere rescatar la energía cósmica del Ande y sus posibilidades fabulosas de cambio y transformación social. Su comparación en su tesis (por oposición) del caballo/patrón versus el cóndor/comunero nos revela su apuesta por la conjunción entre lo tradicional y la posibilidad de una modernidad que el socialismo provee.

De igual modo, la transmutación opera en él mismo. El espíritu de Arguedas se desplaza hacia el narrador huancavelicano, pues ambos han bebido de la realidad andina desde adentro y poseen una mirada devota y militante a la vez, de los problemas del Perú tierradentro. ${ }^{12}$

\section{Narración y representación andina}

Julián Ayuque publica su primer cuento "El Pastor de Dios" en 1975, en la revista "Proceso" de la Universidad del Centro, publicación que editaban entre otros, Manuel Baquerizo, Sybila Arredondo y Waldemar Espinoza. Luego otras nueve narraciones cortas aparecen en "Ama Llulla", "Mundo Andino" y "Ondas Isabelinas". En 1984 publica su novela corta "El Noble Manchego".

"El Pastor de Dios" es una sátira de los curas de pueblo, de su capacidad de explotar y enajenar a los campesinos. El de Castrovirreyna es un "gordinflón, inflado de primicias y grasa ajena". En el cuento no sólo utiliza onomatopeyas para graficar el encuentro entre el quechua y le castellano -"cocorocoóo" canta el gallo al amanecer y, "¡Huac, huac, huac!" ladran los perros en la estancia. "Hachis, hachis, hachis" o "waq, waq, waq" gruñen los zorros en "Juan Burro" (1982).

También es leal con la toponimia local (Qocha-Qocha, Willkapunku, Sapanqeñwa,) y su función es la moraleja para denunciar a los explotadores. Sus personajes son antagónicos: en el "El Pastor de Dios" de un lado están el monaguillo Honorato Charapaqui, los padres de Rebequita, Paulino Escobar y Marcelina Arteaga y del otro, el cura Girondio y el sargento Morte. Estos últimos representantes del poder, tienen apellidos singulares: Girondio podría ser una transformación de Girón -apellido misti de Huancavelica- y Morte que evoca la muerte.

\footnotetext{
11 "Llegó hasta nosotros un movimiento de la multitud como un oleaje" (Los ríos profundos).

12 Un resumen muy breve de la tesis aparece en la compilación de Juan Larco "José María Arguedas: valoración múltiple" La Habana: Casa de las Américas, 1972.
} 
"Niñita Luna" (1981) y "Juan Burro" son las conversiones literarias de dos relatos andinos que se relacionan con el origen de la luna y la pugna entre un burro aliado del ser humano y el zorro dañino. Esta incursión narrativa en la tradición oral ha tenido sus antecesores en destacados intelectuales que la estudiaron en la sierra central como Arguedas, Emeterio Cisneros, Adolfo Vienrich y Pedro Monge.

\section{Escenas de casa}

"El Noble Manchego" (1984) es una corta novela ambientada en Castrovirreyna y tiene como escenario los poblachos andinos y su relación conflictiva aunque también avenida con las haciendas. Pero trata particularmente de una, la hacienda Sinto que fuera propiedad del abogado Celestino Manchego Muñoz, ministro de Fomento del gobierno de Leguía. ${ }^{13}$

La novela está insertada en un conjunto de escenas que no sólo recrean la vida rural de la época, sino también está compuesta por la tradición oral y que deja la impresión de ser un conjunto narrativo disforme, con fragmentos relativamente autónomos.

La novela (124 páginas) está construida con mucho de los recuerdos del autor, tiene pues un halo autobiográfico. Trata de un ternero bayo (manchego) que crece en los pastizales de Castrovirreyna y quien Eustaquio (el hijo de Gertrudis) ha entablado una relación de entrañable cariño. La relación niño/animal revela una unción y una solidaridad entre el hombre andino y la naturaleza en un marco de afectividad y de reciprocidad. Obviamente Eustaquio es Julián que recorre con su toro encariñado los parajes de Qalasaywa, Izcuwatiana pertenecientes a Sinto. Para pagar los estudios de Eustaquio en Ica, la madre vende a Manchego por 8 mil soles a un comerciante apodado Qolquepisco (pene de oro). En esas escenas el autor despliega un lenguaje naif, con una sencillez narrativa que muestra sin ambigüedades su castellano andino:

"-la conversación está buena- diciendo se juntó al grupo Wilde, un monigotereposado y ojos brillosos que estudiaba en el Convento de Cuzco" (61)

Su ingenuidad se mezcla con cierto desorden en la construcción del texto. Por ejemplo cuando relata una tradición local donde un ex -sacristán devoto de San Roque (patrono de Castrovirreyna) se enfrenta a un asesino disfrazado con un hábito franciscano (71) y que luego una página más adelante (72) es transformado en un "ayudante del yanki".

\section{Danza de luna llena}

En 1991 publica un texto con cinco cuentos con el título de Danza en Luna Llena (Danza en Luna Ilena, El pájaro de siete colores, Los hijos del cura,

${ }^{13}$ Celestino Manchego Muñoz fue el impulsor de la construcción del ferrocarril que llega a Huancavelica en 1926. No obstante ser un político conservador sorprendió en la Asamblea Nacional de 1920, al proponer el voto para las mujeres. Natural de la comunidad de Oqollo en Castrovirreyna, estudió leyes en la Universidad del Cuzco y gracias a su matrimonio con la huancaína Georgina Gelicich, es que pudo comprar la hacienda Sinto. 
Gallinazos sin alma y Rubicunda). Estos tienen en común la denuncia social incisiva. Sus personajes son construidos como arquetipos de la explotación como el cura, el comerciante o el hacendado, que son ridiculizados en curiosas escenas de inversión social.

Huamán y Socualya (1995) anotan que estos cuentos pueden ser inscritos en el género de lo real-maravilloso. Quizás lo sea en el sentido que le da LópezBaralt (1988:19-23), en que el principio del género se remonta al "viaje a la semilla" o a los orígenes del encuentro entre el Yo amerindio y el Yo europeo, en que ambos narran los maravilloso y lo inédito a través de la conjunción entre la realidad y la fantasía. Pero creemos que también tiene su explicación en un contexto de violencia y subordinación que significó la colonización. Así los pueblos amerindios tradujeron en sus términos y con una narración "mágica", bilingüe o híbrida, sus deseos de trascender lo indeseable.

Lo que si podemos decir es la oralidad y la superposición del orden social y natural se superponen, como un rasgo propio de las sociedades americanas: en "Danza de luna llena" el gentil participa como bailarín en la fiesta de la trilla del plenilunio y luego al amanecer, solo quedan sus huesos.

Este cuento tomado como modelo, también nos muestra sus personajes literarios ataviados de metáforas quechuas: (Gertrudis) hermosa muchacha "la más codiciada" con "senos de poroto madurado" y "ojos de habas" amante de la danza y el canto de la trilla". "Gertru, Gertrudis, ya no tenía ganas de vivir sin verte. Donde estuviste_floreciendo".

En "Los hijos del cura" el chiste andino se escurre con gracia: "Ylacha está alegre porque seguro su piojo habrá parido liendre hembra- se burló Ipicha". Y también están los morfemas afectivos quechuas: Ipicha (Epifanio), Ilacha (Hilarión), Achi (Asunción), Vitucha (Victoria), Baltuco (Baltasar), Antush (Antonia), Shisha (César).

\section{La poesía quechua}

La poesía de Ayuque es poca y está dispersa en versiones mecanografiadas de revistas como "Tokapu" (1971), el "Amauta Isabelino" (1980) y nuevos poemas recientemente publicados en "Waira Taki", un libro con formato bilingüe.

\section{Huamanripita}

que floreces en el rostro de los cerros, que creces sólo con las caricias de la nieve, hierba muy querida por el Dios Wamani, que sólo te haces besar con el viento frío, visitada sólo por los cóndores.

Quizás su poética sea tributaria de los grandes traductores de la naturaleza animada y del sentimiento aldeano como la poesía chola de Luís Nieto o la nostalgia bucólica de Mario Florían en Pedro Palana o Urpi: 
¿Qué labio de cuculí es más dulce, que lágrima de quena más mielada, que tu canto que cae como lluvia pequeña, pequeñita, entre las flores?

Pastorala.

Pastorala.

(Urpi)

\author{
Mullaquita del Morro Blanco \\ tú le socorrerás \\ a los buenos jóvenes \\ transformadores del mundo, \\ cuando te digan tenemos sed \\ a sus boquitas le sacudirás tu rocío \\ cuando te digan tenemos hambre \\ a sus boquitas \\ le soltarás tu fruto colorado
}

(Wayra Taki)

Si bien Florián, nacido en la aldea contumacina de Nanshá tuvo una experiencia rural vital, su condición de mestizo cajamarquino hace que su imaginario gire en torno a lo "inca" como sistema interpretativo de la identidad peruana. Más bien las ideas poéticas de Ayuque pueden estar cercanas también al registro militante del orcotuneño Hildebrando Pérez Grande en "Aguardiente".

Andahuaylas es leña, leña ardiendo

en una cocina de barro, en cada recuperación de tierras.

El primordialismo de Ayuque combina pues, la visión transparente del paisaje y del ethos andino con la denuncia social:

¿Por qué se apaga

en los ojos de los pobres?

¿Por qué la flor se marchita

con las sonrisas de los niños?

En mi pueblo

la amarga tristeza

se lleva mi alegría

al cementerio;

el hambre asesina mis energías;

los gringos

roban el corazón de oro

de mi poderoso Wamani

(Wayra Taki) 
En algunos artículos el autor ha escrito no sólo sobre el valor del Arguedas comprometido, sino también sobre Javier Heraud (1972), Julián Huanay (1974), Luís de la Puente (1977), Manuel Scorza (1984) y Horacio Zevallos (1984).

Y es aquí donde la comparación con la poesía vanguardista de la sierra central (1930-1940) con la trascendencia de Julián Huanay se torna ineludible. En efecto se puede rastrear en la poética de Ayuque, a los jaujinos Moisés Ortega Rojas (Confidencias para el pueblo) y Víctor Mazzi (Poemas a Mariátegui, 1967). Este último, uno de los más representativos de la poesía proletaria peruana:

ROSA, camarada mía aquí te entrego la luz de mi canción armada para mañana.

Creo que también tiene antecedentes en Augusto Mateu Cueva (Gualda y rosicler 1940). Este escritor nacido en Masma en 1905 y que desde 1928 trabajó como obrero en Morococha hasta su muerte acaecida en 1969, no era al decir de Baquerizo (65): "un admirador beato del pasado, ni apologista unidimensional del terruño y de la aldea. Para él tenían las misma importancia el campo y la ciudad, la tradiciones y el porvenir, la provincia y el anchuroso universo". Su socialismo y vanguardismo allanan el camino por el que transitarán después, muchos escritores de la región central. ${ }^{14}$

Con Julián Huanay (1907-1969) lo vincula no sólo el relato con propósitos políticos sino también con la "situación" del autor. "Invicto dirigente sindical" según el juicio de Apolinario Mayta (1979:185), fue chofer de taxi con 17 ingresos a la cárcel por sus ideas y su actividad gremial.

En su obra más conocida "El retoño" (1950) se narra en primera persona la historia de Juanito, un niño huérfano del valle del Mantaro que huye de su "hogar" para iniciar su aventura adolescente en Lima.

Sin embargo antes de recalar en la gran ciudad, se queda en La Oroya en donde empieza su formación en los sindicatos. Novela de aprendizaje, quizás esté emparentada con la gesta literaria de Gorki y los principios elementales del realismo social. ${ }^{15} \mathrm{El}$ dramatismo y la denuncia de las condiciones de los mineros de la zona (La Oroya, Morococha, Caspalca) discurren en sus páginas.

El final es sólo un umbral inacabado que abre las posibilidades de vida del protagonista y que es reemplazada por la vida real que la protagoniza el autor.

\footnotetext{
14 Ayuque manifiesta en una conversación sostenida el 17 de mayo del 2012, que sus influencias tempranas que moldearon su poesía fueron Andrés Alencastre (Killkuwaraka), y César Guardia Mayorga. El primero un hacendado cuzqueño, el segundo filósofo marxista de fuste.

${ }^{15}$ Baquerizo (1993) hace un breve estudio del estilo narrativo de El retoño. En él, encuentra no sólo la mirada infantil y el tópico de la migración, sino también una visión lineal y ordenada del mundo por la distancia que existe entre la época de la historia y el hecho de contarla. Es decir, muchas veces el mito y la memoria (¿son distinguibles?) cercenan la historia y alisan las contradicciones.
} 
"Tenía hambre. También tenía miedo a la gran ciudad desconocida que se alzaba frente a mí. Así, con muchas dudas y grandes temores, me quedé, de pie, en el umbral de la puerta del Hospital Dos de Mayo".

Con el tema de/ y en los extramuros de la ciudad, Julián Huanay escribiría el libro de relatos "Suburbios" (1968) en donde incursiona al igual que Congrains en la nueva narrativa urbana.

\section{Epílogo}

La literatura huancavelicana eclosiona en los años 50 y transita por diversos momentos que están relacionadas con el fortalecimiento de sus clases medias justamente al entrar en una crisis profunda la reproducción de su clase terrateniente.

De los estudios folklóricos de Quijada Jara (nacido casi en la frontera con Junín) al realismo señorial de Tulio Carrasco, Julián Ayuque representa un indianista de nuevo cuño que supera el regionalismo que había inundado la literatura de provincias. ${ }^{16}$

Julián Ayuque no solo escribe sobre Huancavelica y milita en ella, sino que en una generación posterior Zein Zorrilla expresará esa celebración andina con el cosmopolitismo de una región ya articulada con la sociedad "nacional".

La narrativa y la poesía de nuestro escritor de Castrovirreyna traducen no sólo el paisaje alto-andino y su vinculación con lo silvestre, sino también con sus vivencias campesinas enmarcadas en comunidades "morales". Este sentimiento y esta expresión están además conjugados con una mirada política de la situación del escritor y su medio.

Finalmente, tradiciones fuertemente enraizadas en la literatura andina (y no sólo de ella) como el costumbrismo, el telurismo, el indianismo y el cholismo se funden, y de ellas cristalizadas, surge la narrativa de Ayuque, subalterno entre los subalternos, pero central para nosotros, en la literatura huancavelicana.

\footnotetext{
${ }^{16}$ Siguiendo la senda de los hermanos Bolaños Díaz: Julio Petrovick y Serafín Delmar; la provincia de Tayacaja reúne a narradores que quizás sean los más representativos del departamento ya lejos de su "zona nuclear". Entre ellos podemos mencionar a Carlos Zúñiga Segura, Antonio Muñoz Monge, José Oregón Morales (el de Kutimanco y otros cuentos, 1988), Alberto Chavarría Muñoz, Alfredo Gutarra Luján y el recientemente galardonado Percy Galindo Rojas, autor de "Como los verdaderos héroes" (2008).
} 


\section{BIBLIOGRAFÍA}

Arguedas, José María

1957 "El valle del Mantaro y la ciudad de Huancayo: un caso de fusión de culturas no comprometidas por la acción de las instituciones de origen colonial" Tesis de bachillerato en Etnología, Lima: UNMSM.

1969 "La agonía de Rasu-Ñiti" Lima: Populibros.

1972 "Los ríos profundos" Lima: Retablo de Papel.

Arroyo Posadas, Moisés

1980 "La correspondencia de José Carlos Mariátegui a Jauja" En Allpanchis (16)

Arroyo Aguilar, Sabino

1987 "Algunos aspectos del culto al Tayta Wamani" Lima: UNMSM.

Augé, Marc

1998 "El viaje imposible" Barcelona: Gedisa.

Ayuque, Julián

1971 "El Wamani en la "Agonía de Rasu-Ñiti" de José María Arguedas" tesis de Bachillerato en Humanidades, Huancayo: UNCP.

1972 "Búsqueda de una sociedad justa en la poesía de Javier Heraud" En Correo (Huancayo), 14 de Abril.

1973 "El hombre y la naturaleza en "Agua" En Revista de Humanidades (2), Junio

1974 "Existe literatura nacional en el Perú" En La Voz de Huancayo, 2 de Diciembre.

1974 b "La narrativa de Julián Huanay" (mimeo)

1975 "El Pastor de Dios" En Proceso (3)

1977 "Parábolas de Luís de la Puente Uceda" En Wari (marzo-abril).

1982 "Juan Burro" En Ama LLulla (6)

1983 "La Niñita Luna" En Ama Llulla (7)

1984 a "El noble manchego" Huancayo: Esparce.

1984 b "El cerco imperialista en "Redoble por Rancas" En Correo, 13 de Febrero.

1984 c "Horacio Cevallos: Amauta y Poeta del Pueblo" En La Voz de Huancayo, 2 de Enero.

1984 d "El realismo socialista: resplandor y sombras" En Ondas Isabelinas (noviembre)

1995 "Danza en Luna llena" Lima: Dolorier.

n/e "Wayra Taki (El Canto del Viento)", Lima.

s/f "Retazos de Vida" (apuntes autobiográficos) inédito.

Baquerizo, Manuel

1993 "El punto de vista narrativo en El retoño de Julián Huanay" En Aportes (Huancayo) 1, junio-julio.

1998 "La conciencia de la identidad en la literatura de costumbres de la sierra central" Huancayo: Centro Cultural Arguedas. 
Bourdieu, Pierre

1990 "Sociología y cultura" México: Grijalbo.

Cabral, Amílcar

1973 "La cultura fundamento del movimiento de liberación" En El Correo, Unesco (26)

Callois, Roger

1996 "El hombre y lo sagrado" México: FCE.

Carrasco, Tulio

1955 "Mala entraña" (cuentos del Ande) Lima: Círculo de Novelistas Peruanos.

Escobar, Alberto (selección y prólogo)

1958 "Cuentos peruanos contemporáneos" Lima: Ediciones Peruanas.

Flannery Kent, Joyce Marcus y Robert Reynolds

1989 "The flocks of the wamani: a study of llama herders on the punas of Ayacucho, Perú" San Diego: Academic Press.

Florían, Mario

1969 "Antología poética" Lima: Casa de la Cultura del Perú.

Fox, Inman

1997 "La invención de España" Madrid: Cátedra.

Huamán María Beatriz y Mercedes Socualaya

1995 "Algunos aspectos socio-económicos culturales del mundo andino en "Danza de Luna llena" Informe para optar el título de Lienciadas en Pedagogía y Humanidades: Español y Literatura, Huancayo: UNCP.

Huanay, Julián

1969 "El retoño" Lima: Casa de la Cultura del Perú.

Landa, Ladislao

2010 "José María nos engañó: las ficciones de la etnografía" En Revista de Crítica Literaria Latinoamericana 36 (72)

Lauer, Mirko

1997 "Andes imaginarios: discursos del indigenismo 2" Lima: Sur.

López-Baralt, Mercedes

1988 "Icono y Conquista: Guamán Poma de Ayala” Madrid: Hiperion.

López-Soria, Ignacio

1981 "Historia de la Universidad Nacional de Ingeniería: Tomo I: Los años fundacionales (1876-1909)" Lima: UNI.

Mayta Inga, Apolinario 
1979 "Enciclopedia Departamental de Junín, tomo 2. Literatura" Huancayo: Enrique Chipoco.

Merlino Rodolfo y Mario Rabey

1983 "Pastores del altiplano andino meridional: religiosidad, territorio y equilibrio ecológico" En Allpanchis (21).

Mudimbe, Valentín

1988 "The invention of Africa" NY: James Coleman.

Nieto Degregori, Luís

2000 "El debate entre andinos y criollos en la narrativa andina peruana última" En Márgenes (17)

Ortiz, Alejandro

1993 "La Pareja y el Mito: Estudio sobre las percepciones de la persona y de la pareja en los Andes" Lima: PUCP.

Pérez, Hildebrando

1978 "Aguardiente y otros cantos" La Habana: Casa de las Américas.

Quijada Jara, Sergio

1944 "Estampas huancavelicanas" Lima: Tipografía Salas.

1957 "Canciones del ganado y pastores" Lima: Villanueva.

Pratt, Mary Louise

2010 "Ojos imperiales: Literatura de viajes y transculturación" México: FCE.

Rénique, Gerardo

1978 "Movimientos campesinos en la Sociedad Ganadera del Centro (19101950)" en Allpanchis (11-12)

Ricard, Xavier

2007 "Ladrones de sombra. El universo religioso de los pastores del Ausangate (Andes surperuanos)" Lima: IFEA/Centro Las Casas.

Salazar Bondy, Sebastián

1974 "Lima la horrible" Lima: Peisa.

Smith, Gavin

1989 "Livelihood and resistance: Peasant the politics of land in Perú" Berkeley: University of California Press.

Urrutia, Jaime

1994 "Los pocras o el mito de los huamanguinos" en La diversidad huamanguina: tres momentos en sus orígenes, Lima: IEP.

Vich, Cynthia

2000 "Indigenismo de vanguardia en el Perú: Un estudio sobre el Boletín Titikaka" Lima: PUCP. 